Tjalling C. Koopmans Research Institute

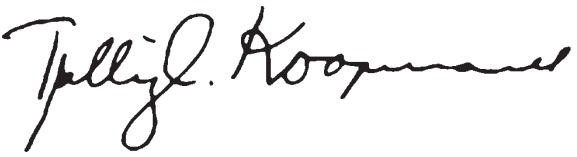

Discussion Paper Series nr: 09-04

\title{
Social capital and health across European countries
}

Bas van Groezen

Rashmi Jadoenandansing

Giacomo Pasini 


\section{Tjalling C. Koopmans Research Institute Utrecht School of Economics \\ Utrecht University}

Janskerkhof 12

3512 BL Utrecht

The Netherlands

telephone +31302539800

fax +31302537373

website www.koopmansinstitute.uu.nl

The Tjalling C. Koopmans Institute is the research institute and research school of Utrecht School of Economics.

It was founded in 2003, and named after Professor Tjalling C. Koopmans, Dutch-born Nobel Prize laureate in economics of 1975.

In the discussion papers series the Koopmans Institute publishes results of ongoing research for early dissemination of research results, and to enhance discussion with colleagues.

Please send any comments and suggestions on the Koopmans institute, or this series to J.M.vanDort@uu.nl

ontwerp voorblad: WRIK Utrecht

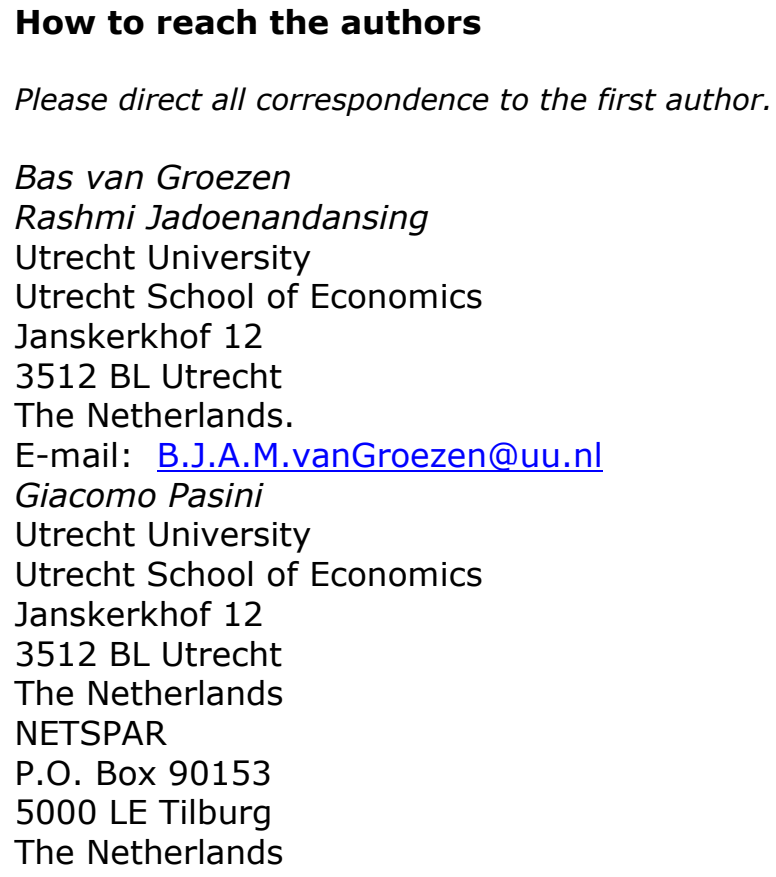


Utrecht School of Economics

Tjalling C. Koopmans Research Institute

Discussion Paper Series 09-04

\title{
Social capital and health across European countries
}

\author{
Bas van Groezena \\ Rashmi Jadoenandansing ${ }^{a}$ \\ Giacomo Pasiniab \\ ${ }^{\text {aUtrecht School of Economics }}$ \\ Utrecht University \\ 'NETSPAR, \\ Network for Studies on Pensions, Aging and Retirement
}

April 2009

\begin{abstract}
We compare the effect of trust and civic participation on self-assessed health across ten European countries. We find that, after controlling for a rich set of socio-economic characteristics, for actual health status and for health-related behaviours, trust has a significantly positive effect on perceived health in Sweden and in Germany, but none in the other countries. Civic participation does have a positive and quite similar effect in all countries. Our conclusion is that they measure two different aspects of social capital that must be treated separately.
\end{abstract}

Keywords: Panel Data, Wage Distribution, Inequality, Mobility

JEL classification: $\mathrm{I} 12, \mathrm{~J} 14$

\section{Acknowledgements}

This paper uses data from SHARE Wave 1, as of December 2008. SHARE data collection in 2004-2007 was primarily funded by the European Commission through its 5 th and 6th framework programmes (project numbers QLK6-CT-2001- 00360; RII-CT- 2006-062193; CIT5-CT-2005-028857). Additional funding by the US National Institute on Aging (grant numbers U01 AG09740-13S2; P01 AG005842; P01 AG08291; P30 AG12815; Y1-AG-455301; OGHA 04-064; R21 AG025169) as well as by various national sources is gratefully acknowledged (see http://www.share-project.org for a full list of funding institutions). 


\section{Introduction}

The determinants of health have been subject of a vast amount of research in, among others, medical science, social science and economics. The seminal paper by Grossman (1972) analyzes health as a durable capital stock which, apart from the initial health that someone genetically inherits, is the outcome of individual decisions concerning lifestyle and the usage of health care. Recently the idea has grown that explaining the differences in people's health status also requires the inclusion of what has become known as social capital. This comprehensive sociological concept, first introduced into the economic literature by Putnam (1995) and Coleman (1988), includes several characteristics such as the feeling of trust and safety, social participation in networks and associations, and norms of mutual aid and reciprocity, which can be present both at the individual and at the community level, and can affect health through several channels. Recent studies have investigated these relationships: Veenstra (2000), Folland (2007) and Petrou and Kupek (2008) focus on a particular country and take into account several possible measures of social capital, while Poortinga (2006), Rostila (2007) and Sirven and Debrand (2008) compare different countries, but along only one measure. A comprehensive survey of studies on the relationship between health and social capital can be found in Islam et al. (2006). This paper adds to the growing body of literature on social capital and health by comparing the effect of two distinct elements of social capital, trust and civic participation), across several European countries. We will focus on health perception, i.e. how healthy people feel, after controlling for objective health and other health-related factors. The main result is that different elements of social capital have a distinct effect on health perception, and these effect are not equal across countries. They therefore measure two different aspects of social capital that must be treated separately. The rest of this paper is organized as follows. Section 2 describes the different aspects of social capital, as well as mechanisms through which it can affect someone's health. In Section 3, the dataset and the empirical analysis are described. Section 4 concludes.

\section{Social capital: Definitions and forms}

Social capital is an umbrella term that covers many features of the connections within and between networks of people, such as social cohesion, social support, social integration, and social participation. Depending on the topic to which this concept is applied (and in empirical research often also on the availability of appropriate data), one or more of these features is used to capture it. A useful distinction is between structural and cognitive social capital, as defined by Islam et al. (2006). Structural social capital are the 'externally observed aspects' of the social environment, mainly including the structure of an individual's network and participation in voluntary organizations. According to this definition, the level of social capital will be different between dissimilar persons because it is the result of individual action, 
as in e.g. Glaeser et al. (2002), who use a model of optimal individual investment decisions concerning the accumulation of social capital. Cognitive social capital, on the other hand, consists of a person's attitudes and values, such as the perception of the level of interpersonal trust and reciprocity, which facilitate cooperation. This second dimension of social capital is likely to be homogeneous within a community: it is a contextual characteristic influencing individual behaviour and perceptions.

Another distinction is that between bonding and bridging social capital, as was put forward by Putnam (1995). Bonding social capital stems from the relations of an individual with persons who are rather homogeneous (the so-called 'inner circle'), such as family and close friends, while bridging social capital captures the social ties between people outside the inner circle but belonging to the same socio-economic group in society (typically people who go to e.g. the same educational, sports or other leisure clubs). However, in this paper we will not use this distinction.

\section{Social capital and health}

Social capital can affect health through several mechanisms. Berkman et al. (2000) provide a comprehensive conceptual model of how social networks influence health. Socio-structural conditions at the macro level, such as culture, public policy, and social change condition the extent, shape and nature of social networks (e.g. the frequency of contacts with other people). This provides opportunities for psychosocial mechanisms at the micro level, which includes social support, social influence, social engagement, and access to material resources. Examples of how this can influence health are directly through emotional support (which prevents depression, stress and loneliness), but also indirectly by increasing the accessibility of information about sickness prevention, healing, or how to find the right care provider. Furthermore, through social contacts, individuals can influence each other's attitudes and behaviours. ${ }^{12}$ This effect will be especially strong if the level of cognitive social capital is high: in a trustworthy society public health care interventions are more likely to be effective, e.g. because people comply with preventive policies such as flu shots, pay attention to anti drugs commercials, follow indications of general practitioners and so on. Finally, a person with more social capital is likely to have better access to material resources, such as income and wealth. This will improve health in several ways, for example by improving access to care or sustaining healthy behaviour which tends to be more expensive than unhealthy behaviour.

We can therefore conclude that social capital affects health in different ways: at the macro level through cognitive social capital, at the individual level through social networks. In order to account for these different mechanisms, we will distinguish between social interactions -

\footnotetext{
${ }^{1}$ More specifically, this goes mostly for bonding social capital: people who are very close like siblings, parents, partners or other close family and friends are more likely to encourage each other to live responsibly and induce healthy behaviours: Contoyannis and Jones (2004), among others, show that exercising, sleeping well and not smoking have 'dramatic' positive effects on health.

${ }^{2}$ Folland (2008) supports this idea by providing a first attempt to model the demand for 'health goods' and 'health bads' as a function of social capital and consumption.
} 
which according to Islam et al. (2006) account for structural social capital - and trust - a measure of cognitive social capital - and test whether they have different effects on health perception.

\section{Empirical analysis}

In this paper, we focus on the effect of social capital on health perception, i.e. how healthy people feel. We define health according to the World Health Organization as '[...] a state of complete physical, mental and social well-being and not merely the absence of disease or infirmity. ${ }^{3}$ Thus, the dependent variable will be a subjective measure of health perception, and, different from most of the literature investigating the effect of socio-economic status on health, we include objective health measures amongst regressors to control for the presence of diseases and infirmities.

The dataset we use combines information from the Survey on Health, Ageing and Retirement (SHARE) and the World Value Survey (WVS). The 2004 wave of SHARE collects cross-national data on socioeconomic characteristics, health status, health behaviour and social networks of persons aged 50 and over. It contains two different types of health status measures: self-reported health and objective measures of health. The former is the dependent variable in our analysis: it is a 5-scale subjective question, where respondents are asked to rate their own health between Poor and Excellent. Among the regressors, we include objective measures of health, in order to control for the presences of diseases and infirmity: the number of limitations with activities of daily living $(a d l)^{4}$ and the number of chronic diseases reported by each individual (chronic)..$^{5}$ Furthermore, we correct for health-related behaviour by including three variables that measure smoking behaviour, drinking (too much) alcohol, and doing moderate or vigourous exercise.

SHARE provides also information to construct a social-interactions variable (sumact), which is the sum of days per month spent on social activities like voluntary or charity work, attending an educational or training course, going to a sports, social or other kind of club, taking part in religious, political or community organization activity. ${ }^{6}$ The measure for cognitive social capital is obtained from the WVS. ${ }^{7}$ The specific question we use is the

\footnotetext{
${ }^{3}$ Constitution of the World Health Organization, Geneva 1946.

${ }^{4}$ Six activities are included: dressing, walking, bathing or showering, eating, getting in and out of bed and using the toilet.

${ }^{5}$ The variable corresponds to the followings diseases: hearth attack, high blood pressure or hypertension, high blood cholesterol, a stroke or cerebral vascular disease, diabetes, chronic bronchitis or emphysema, asthma, arthritis, osteoporosis, cancer or malignant tumor, stomach or duodenal ulcer, Parkinson disease, cataracts and hip fracture or femoral fracture.

${ }^{6}$ For the analysis we used the hyperbolic-sine log transformation of sumact. For details see Burbidge et al. (1988).

${ }^{7}$ WVS, EVS and Zentral Archive are the data archives and distributors of the WVS/EVS data. See European Values Study Group and World Values Survey Association (2006) for a detailed description of the data.
} 
following:

Generally speaking, would you say that most people can be trusted or that you need to be very careful in dealing with people?

1. 'Most people can be trusted'

0. 'Can't be too careful'

Both for SHARE and WVS we know the area of residence of respondents. Thus, we construct area-level averages on WVS respondents of the trust-dummy variable, and then assign it to every SHARE respondent in the same area. The mean of the dummy variable can be interpreted as the fraction of people who trust in the area of residence of the (SHARE) respondent.

Apart from the variables that measure health status and social capital characteristics, we also control for socio-economic variables such as age, income, wealth, years of education and employment status. Table 1 shows all variables that are included in the regression analysis.

\section{Estimation results}

Regressions were run for 10 European countries separately. ${ }^{8}$ For each country there are three specifications: the first includes only trust among the regressors, the second only social interactions, the third includes both measures of social capital. Tables 2-4 show the results of an ordinary least squares (OLS) regression. Standard errors are clustered at the area level, according to Moulton (1990). We also estimated the same set of regressions with ordered probit; these results (see Tables 5-7) are qualitatively similar to the OLS-results.

The first result is that the trust coefficient is significantly positive only in Germany and Sweden, while social interactions matter across all countries (except for one): this is an indication that cognitive social capital and structural social capital affect (perceived) health differently. Trust matters only in Germany and Sweden. Since the average level of trust in these countries is not much different from surrounding countries, the different influences on health of this particular dimension of social capital seem to depend on specific institutional and cultural characteristics. On the other hand, social interactions have a significant effect in all but one of the ten countries, and coefficients, even if significantly different across countries, lie in the rather small interval $[0.55,0.96]$. Such an effect therefore seems not to be driven by cultural or institutional factors: being more sociable has a positive effect on perceived health (ceteris paribus) throughout Europe.

The second result is that trust and sociability are not collinear: trust coefficients do not vary significantly once social interaction is introduced and vice versa. Again, this points in the direction of two clearly distinct effects: the two measures are not different proxies for the same underlying phenomenon.

\footnotetext{
${ }^{8}$ Due to the presence of many missing values for Greece of variables of interest both in SHARE and WVS, we did not include this country in the analysis.
} 
All the other demographic and economic controls have signs and significance in line with the previous literature. Gender, age, marital status and the number of children have no significant effect on perceived health in nearly all countries (except for Belgium and Germany for the age variable, and Belgium for the gender variable). However, being employed instead of unemployed is important in almost every country. Years of education is has a positive effect on health only in Germany, France and Spain. The effects of financial factors is diverse: income matters in Sweden, Germany and France, real wealth is important in the Northern countries, Switzerland and Austria, while financial wealth has a significantly positive effect in the Netherlands, Germany, France, Switzerland, Austria and Italy. Finally, also healthrelated behaviours show a mixed picture: drinking a lot of alcohol is significantly negative for perceived health in some countries, but positive in others. Smoking has a negative effect only in northern countries and Austria. Doing regular exercise is good for (perceived) health in all countries but Switzerland.

Differently with most of the literature investigating the effect of socio-economic status on health, we include on the right hand side of the equation two objective health measures. The reason is somewhat technical: in order to interpret the coefficient in a causal framework, we are implicitly assuming that trust and sociability are not endogenously determined, i.e. that they are determinants of perceived health, and not vice versa. Introducing objective health amongst the regressors, such an assumption can be rephrased as that given a certain objective health status, differences in perceived health do not cause differences in trust nor in the intensity of social interactions. Obviously, the results show that being limited in activities of daily living and having chronic diseases significantly reduce reported health.

\section{Conclusion}

Public health promotion is a prominent objective for policy makers. This requires careful examination of factors that influence health. We estimated the effect of cognitive and structural social capital on perceived health across ten European countries. Cognitive social capital is measured as the trust level in the area of residence of each individual, structural social capital is proxied by hours spent in social activities. The main conclusion is that cognitive and structural social capital have two distinct effects on health. Moreover, trust matters only for Sweden and Germany, while sociability does not display great differences across countries. The first implication is that trust and social interaction cannot be interchanged and should be considered alternative measures of social capital. Secondly, the relation between a country's cultural and institutional features and social capital is not straightforward and depends on the specific dimension of social capital: the social-interaction effect is similar across countries, while trust matters only in two out of ten European countries. 


\section{References}

Berkman, L. F., T. Glass, I. Brisette, and T. Seeman (2000). From social integration to health:. Social Science and Medicine 51(6), 843-857.

Burbidge, J. B., L. Magee, and A. L. Robb (1988). Alternative transformations to handle extreme values of the dependent variable. Journal of the American Statistical Association 83, $123-127$.

Coleman, J. S. (1988). Social capital in the creation of human capital. America Journal of Sociology 94, 95-120.

Contoyannis, P. and A. M. Jones (2004). Socio-economic status, health and lifestyle. Journal of Health Economics 23, 965-995.

European Values Study Group and World Values Survey Association (2006). European and world values surveys four-wave integrated data file, 1981-2004, v.20060423. Technical report.

Folland, S. (2007). Does "community social capital" contribute to population health? Social Science and Medicine 64, 2342-2354.

Folland, S. (2008). An economic model of social capital and health. Health Economics, Policy and Law 3, 333-348.

Glaeser, E. L., D. Laibson, and B. Sacerdote (2002). An economic approach to social capital. Economic Journal 112, 437-458.

Grossman, M. (1972). On the concept of health capital and the demand for health. Journal of Political Economy 80(2), 223-255.

Islam, M. K., J. Merlo, I. Kawachi, M. Lindström, and U. G. Gerdtham (2006). Social capital and health: Does egalitariamism matter? A literature review. International Journal for Equity in Health 5, 1-28.

Moulton, B. R. (1990). An illustration of a pitfall in estimating the effects of aggregate variables on micro unit. Review of Economics and Statistics 72, 334-38. 2.

Petrou, S. and E. Kupek (2008). Social capital and its relationship with measures of health status: Evidence from the health survey for England 2003. Health Economics 17, 127-143.

Poortinga, W. (2006). Social capital: An individual or collective resource for health? Social Science and Medicine 62, 292-302.

Putnam, R. (1995). Bowling alone: Americas declining social capital. Journal of Democracy $6(1), 65-78$. 
Rostila, M. (2007). Social capital and health in European welfare regimes: a multilevel approach. Journal of European Social Policy 17(3), 223-239.

Sirven, N. and T. Debrand (2008). A counterfactual analysis from the survey on health, ageing, and retirement in Europe. IRDES Working Paper (7).

Veenstra, G. (2000). Social capital, SES and health: an individual-level analysis. Social Science and Medicine 50, 619-629. 
Table 1: Variables' description

\begin{tabular}{|c|c|}
\hline trust-w34 & $\begin{array}{l}\text { fraction of people in the area who think most people can be trusted } \\
\text { (based on wave } 3 \text { and } 4 \text { data from WVS) }\end{array}$ \\
\hline lsumact & $\begin{array}{l}\text { total number of hours per month spent on social activities } \\
\text { (hyperbolic-sine logarithmic transformation) }\end{array}$ \\
\hline \multirow[t]{2}{*}{ adl } & number of limitations with activities of daily living \\
\hline & $\begin{array}{l}\text { (dressing, walking, bathing or showering, eating, getting in and out of bed } \\
\text { and using the toilet) }\end{array}$ \\
\hline \multirow[t]{2}{*}{ chronic } & number of chronic diseases among which the following diseases: \\
\hline & $\begin{array}{l}\text { hearth attack, high blood pressure or hypertension, high blood cholesterol, } \\
\text { a stroke or cerebral vascular disease, diabetes, chronic bronchitis or emphysema, } \\
\text { asthma, arthritis, osteoporosis, cancer or malignant tumor, stomach or duodenal ulcer, } \\
\text { Parkinson disease, cataracts and hip fracture or femoral fracture }\end{array}$ \\
\hline gender & dummy variable, 1 if respondent is a woman \\
\hline & age of the respondent \\
\hline age2 & age squared \\
\hline married & $\begin{array}{l}\text { dummy variable, } 1 \text { if respondent is married or in a registered partnership, } \\
0 \text { any other status (never married, divorced or separated, widow) }\end{array}$ \\
\hline nchild & number of respondent's children \\
\hline emplsempl & dummy variable, 1 if employed or self employed (omitted category is retired) \\
\hline unother & dummy variable, 1 if unemployed or in other status (omitted category is retired) \\
\hline iscedy-r & years of completed education \\
\hline \multirow[t]{2}{*}{ linc } & total household income \\
\hline & (hyperbolic-sine logarithmic transformation) \\
\hline \multirow[t]{2}{*}{ rwealth } & household net real assets \\
\hline & (hyperbolic-sine logarithmic transformation) \\
\hline \multirow[t]{2}{*}{ fwealth } & household net financial assets \\
\hline & (hyperbolic-sine logarithmic transformation) \\
\hline $\begin{array}{l}\text { alc } \\
\text { smokecu }\end{array}$ & $\begin{array}{l}\text { dummy variable, } 1 \text { if respondent drinks more than } 2 \text { glasses of alcohol almost every day } \\
\text { dummy variable, } 1 \text { if respondent is currently a smoker }\end{array}$ \\
\hline exer & $\begin{array}{l}\text { dummy variable, } 1 \text { if not physically inactive; physical inactivity is defined as } \\
\text { never or almost never engaging in neither moderate nor vigorous physical activity }\end{array}$ \\
\hline
\end{tabular}




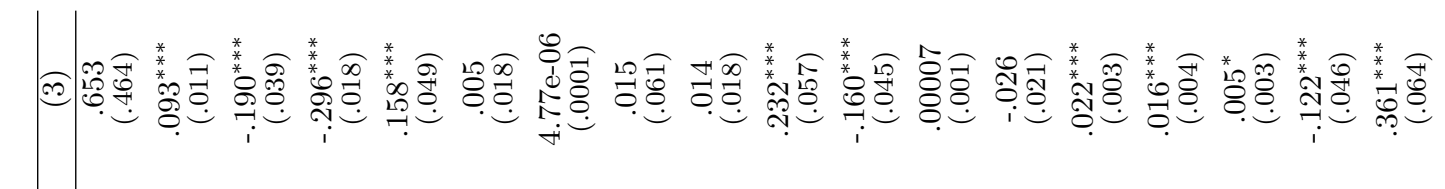

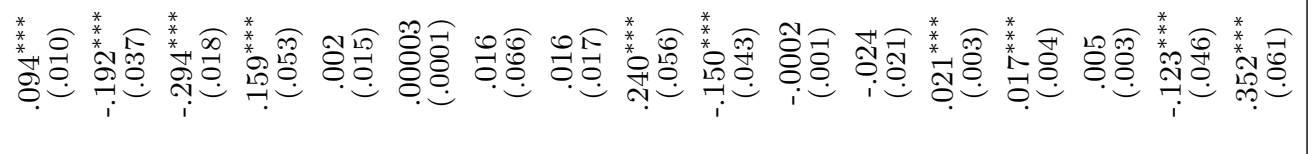

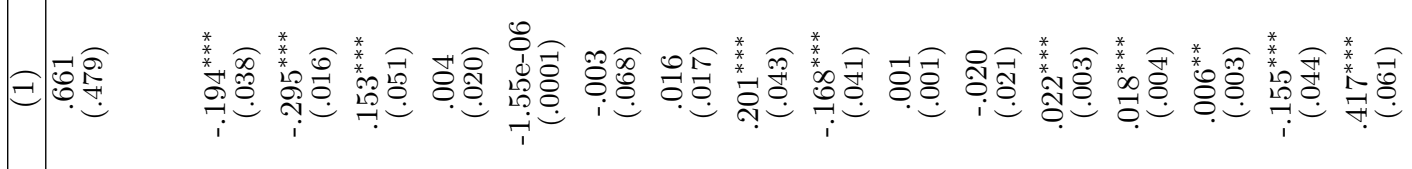

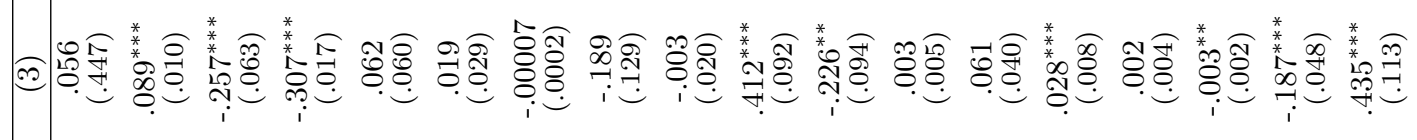

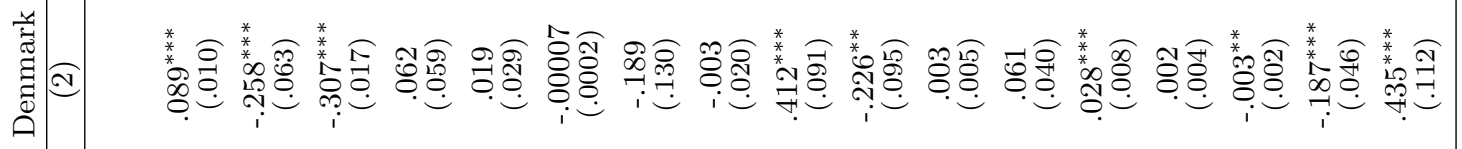

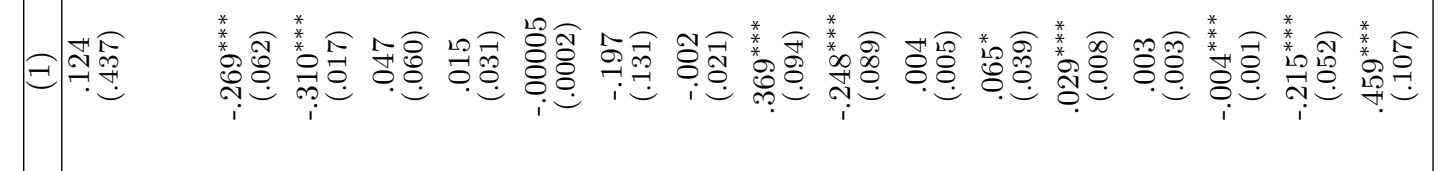

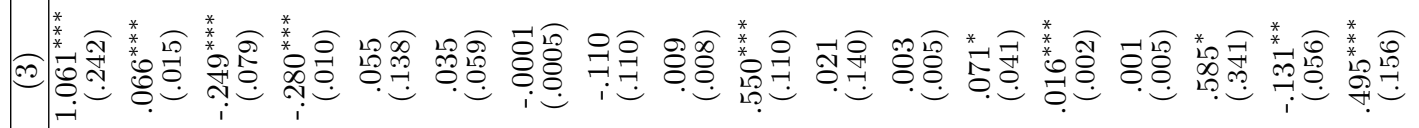

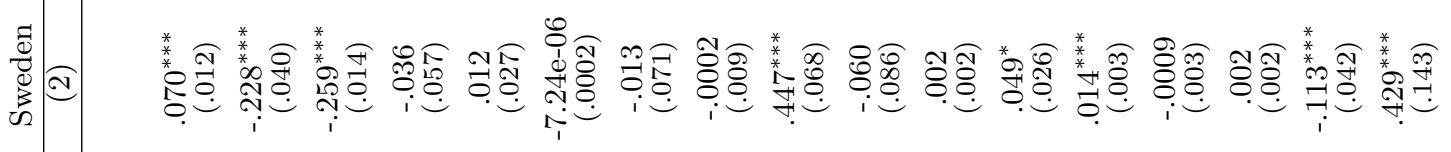

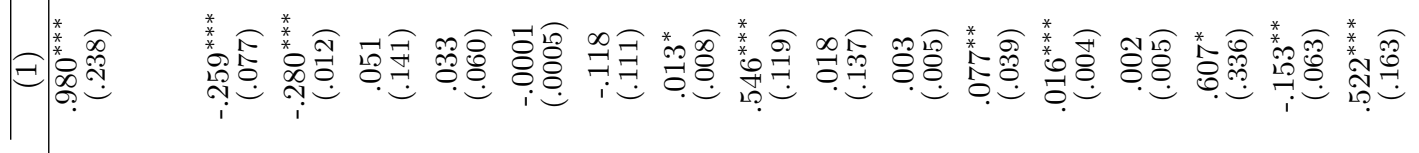

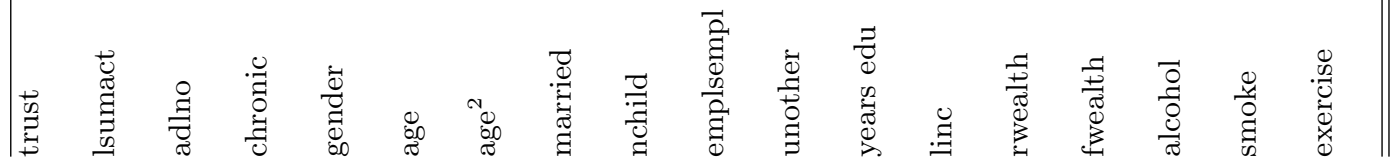




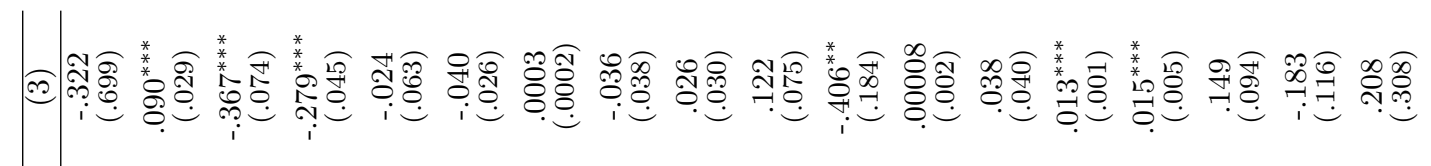

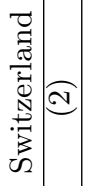

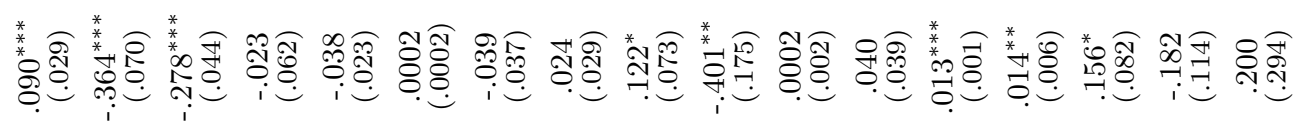

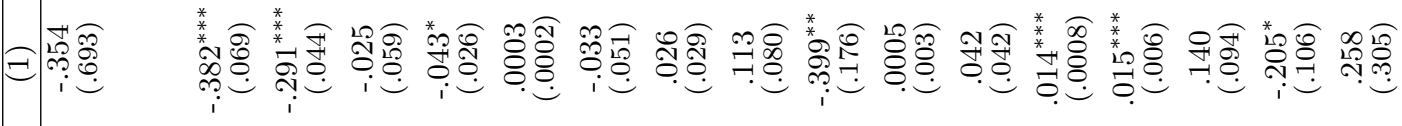

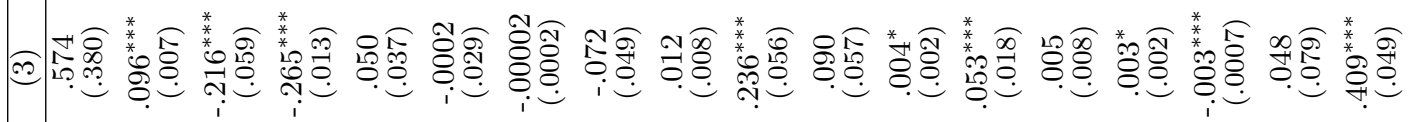

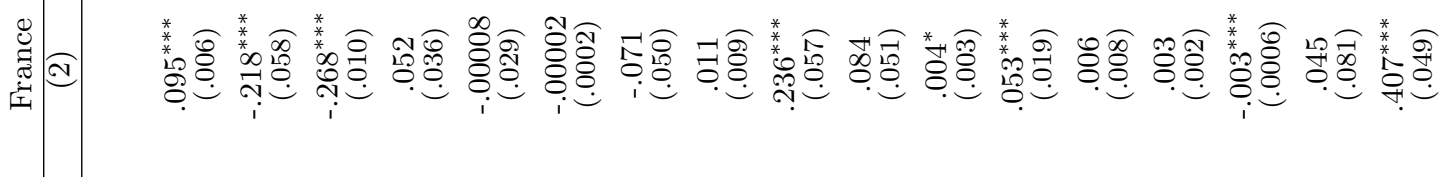

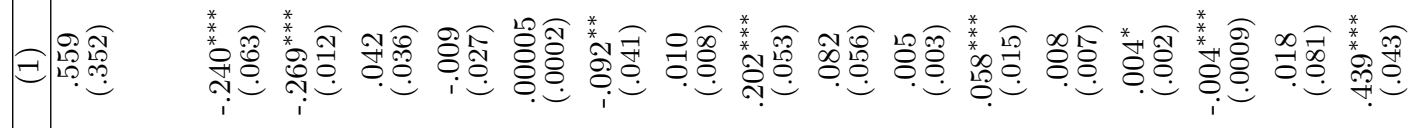

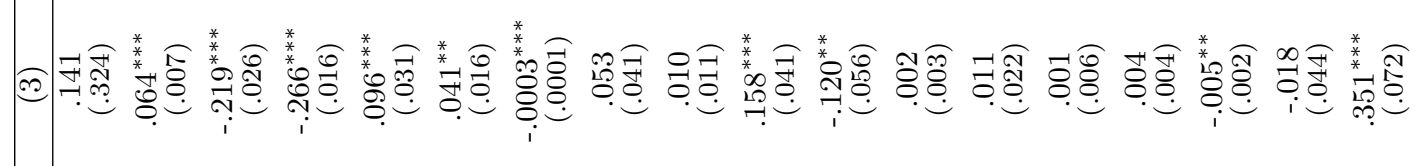

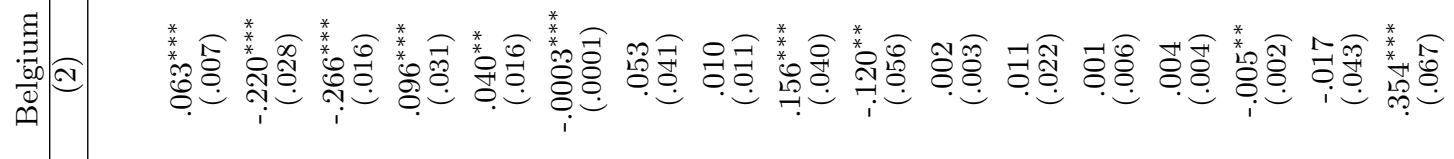

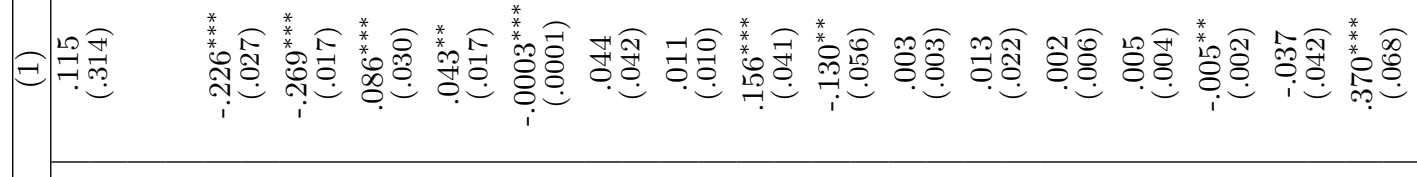

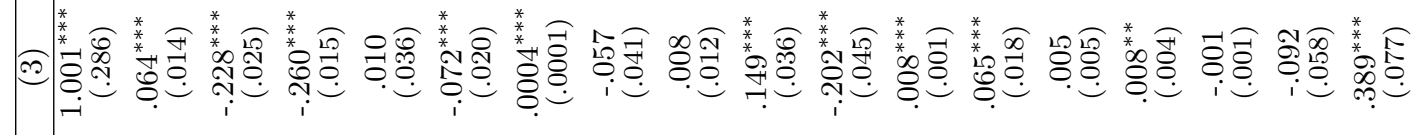

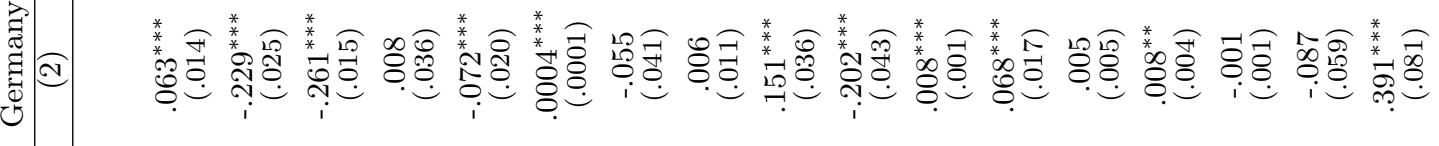

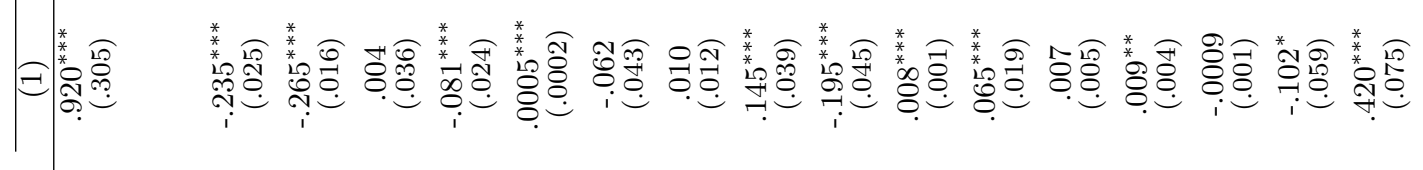

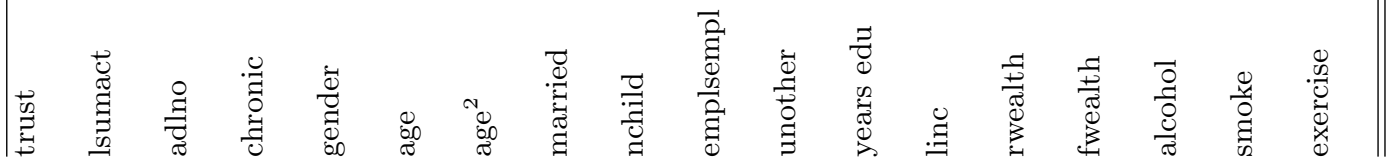




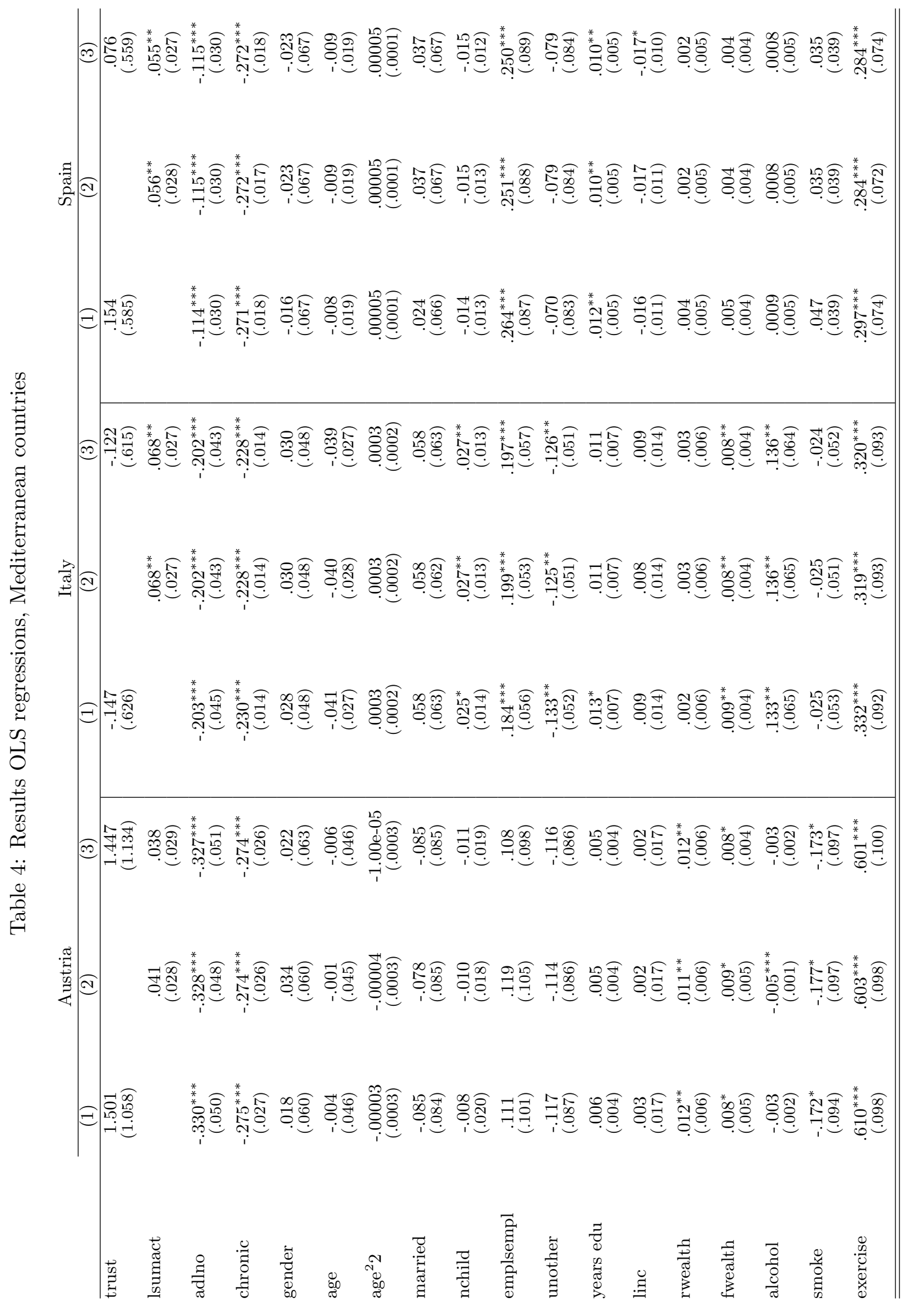




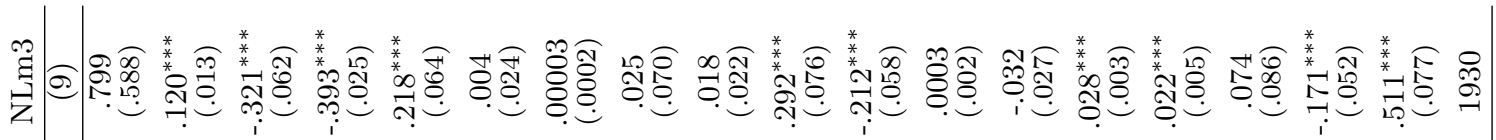

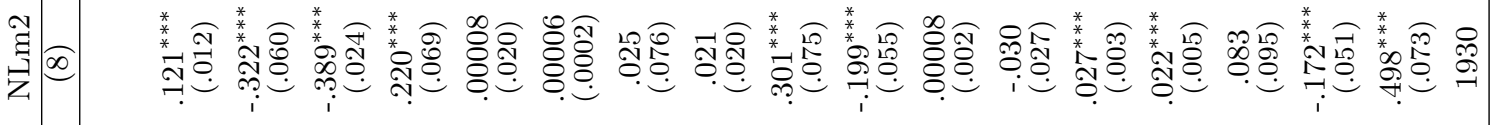

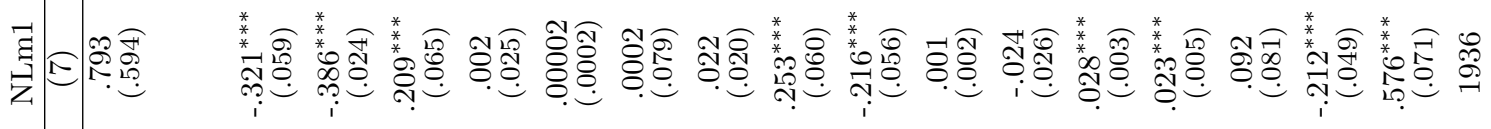

0
0
0
0
0
0
0
0
0
0
00
0
$z$

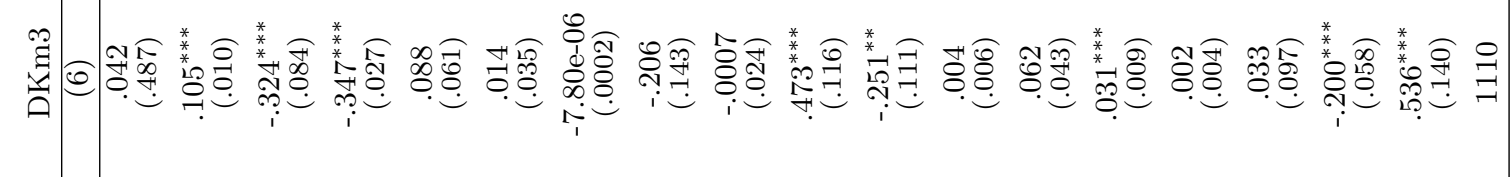

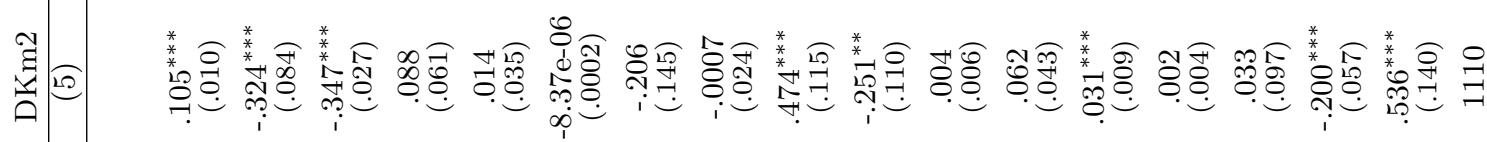

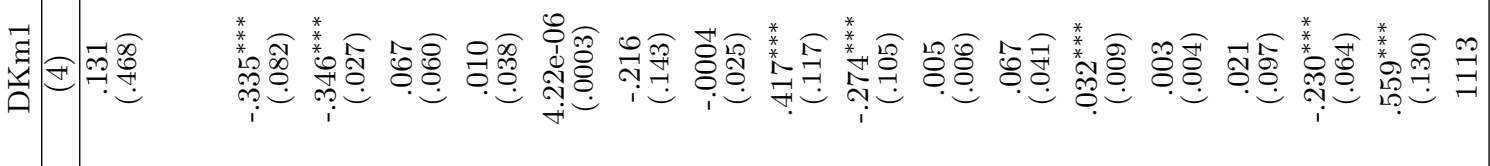

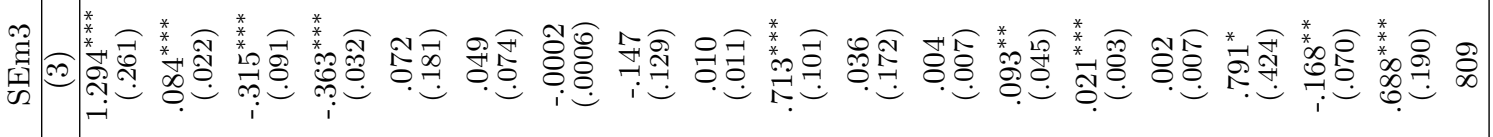

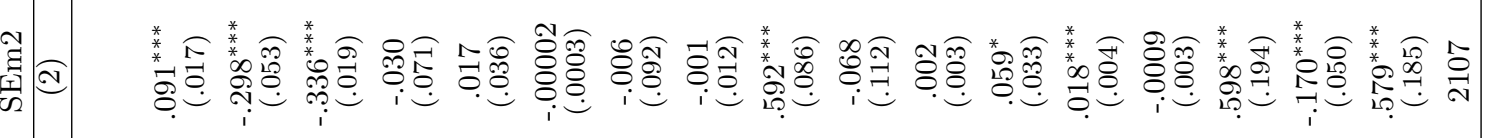

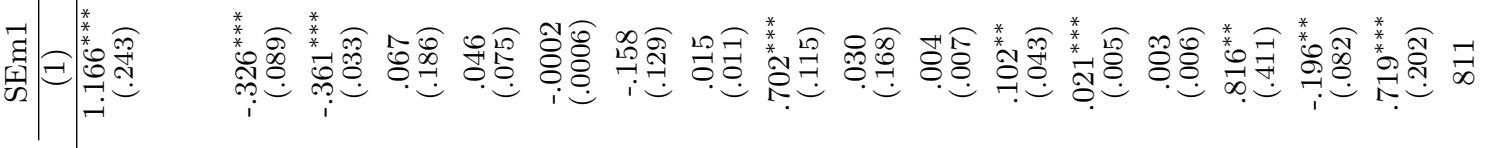

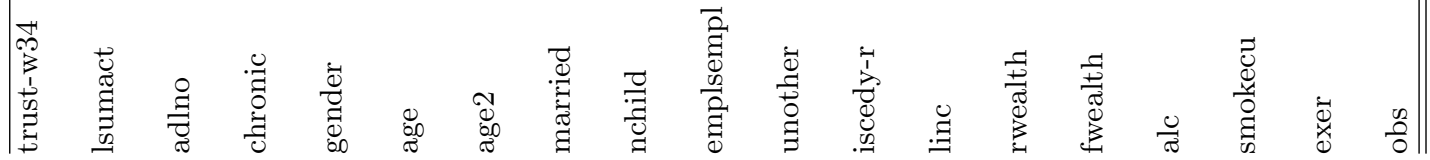




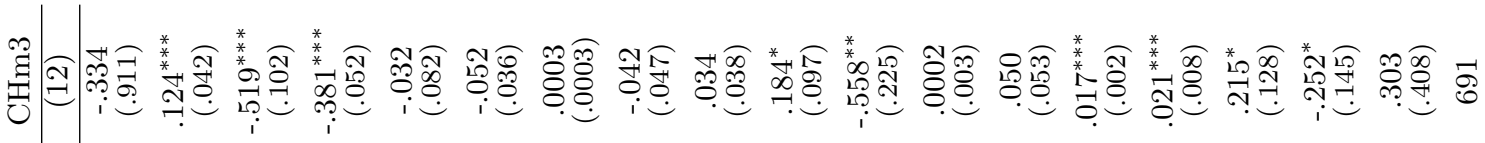

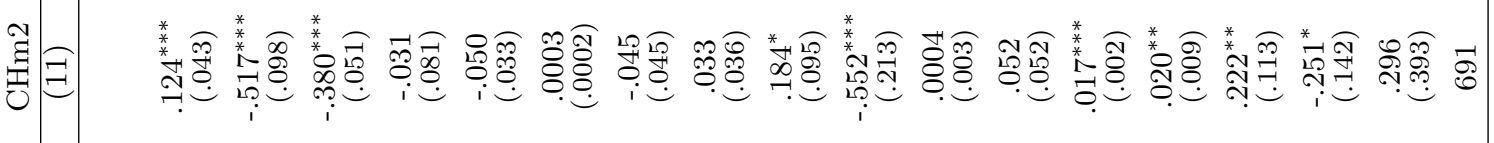

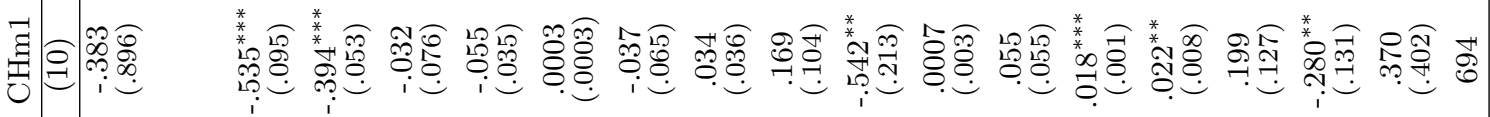

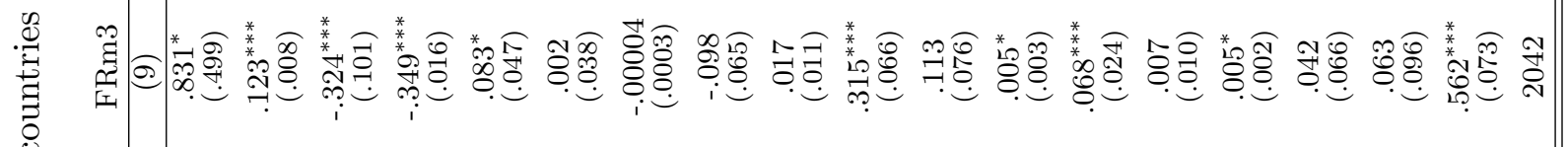
畜

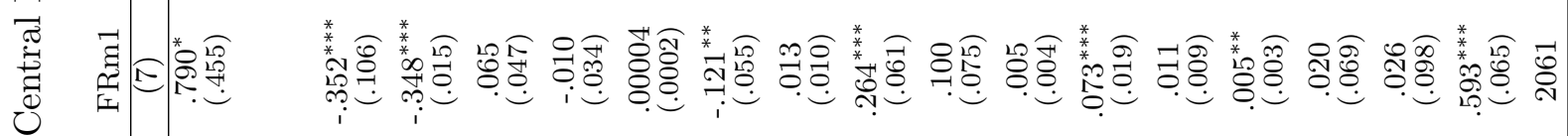

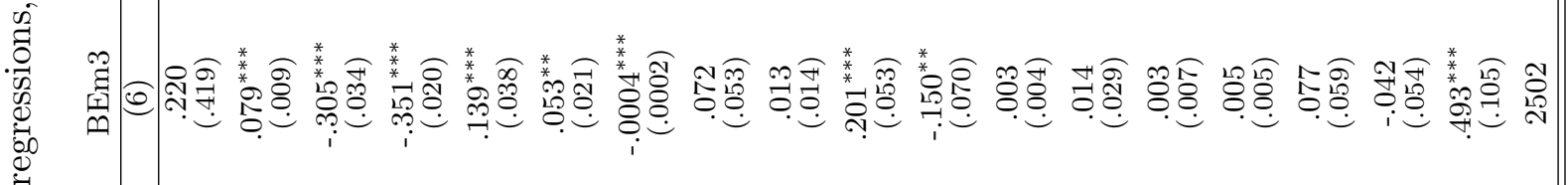

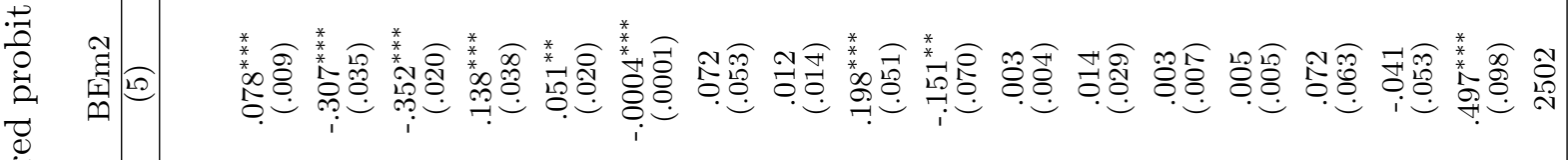
漓

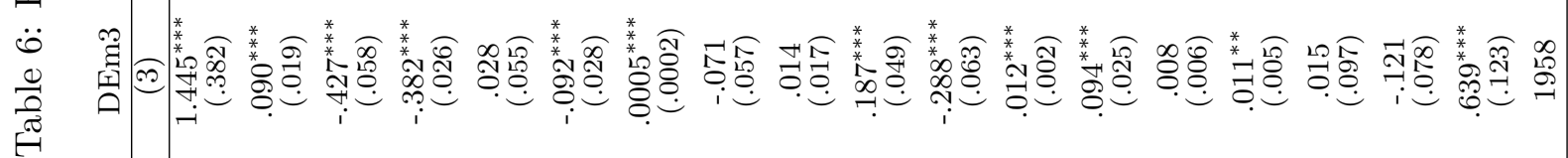

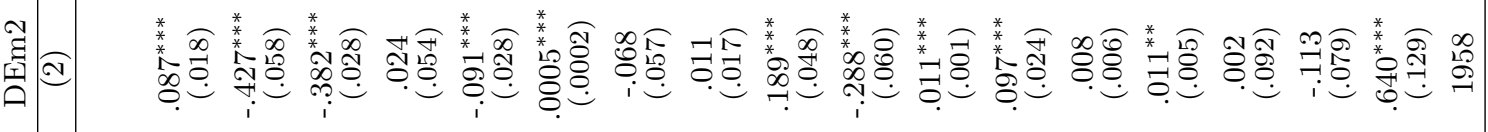

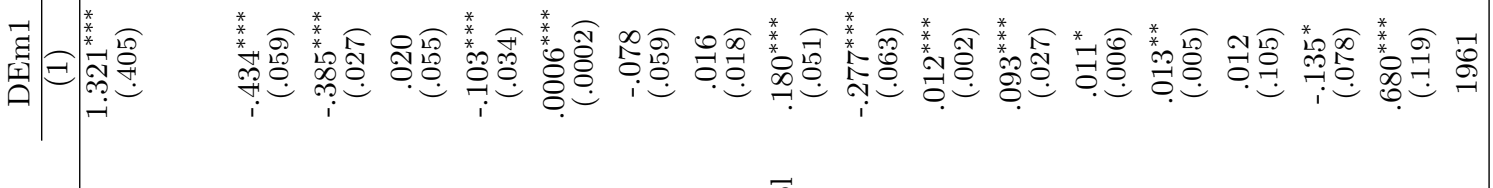

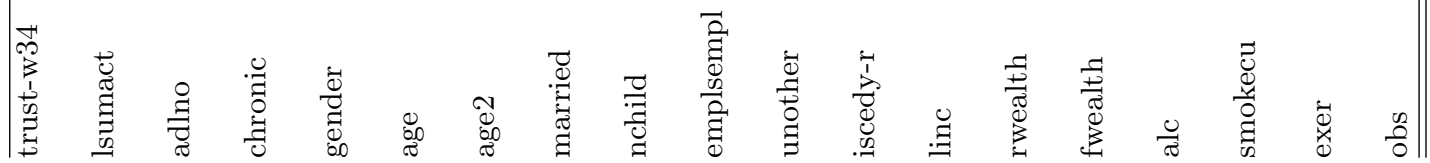




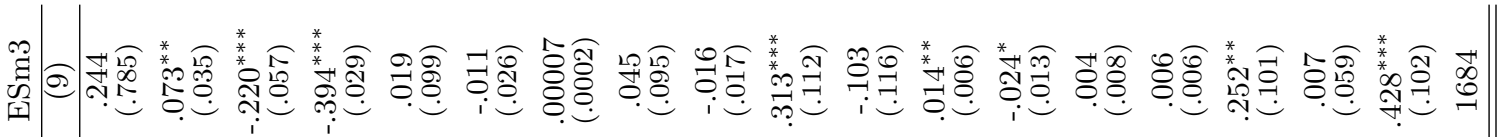

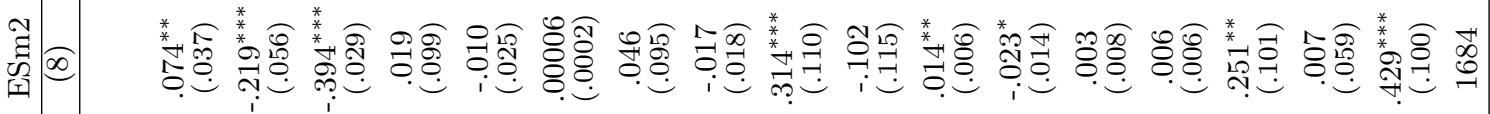

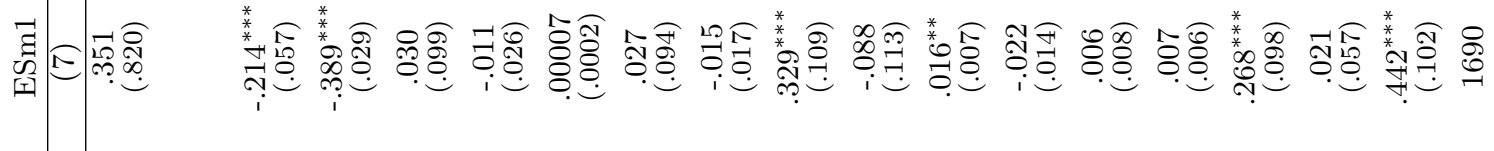

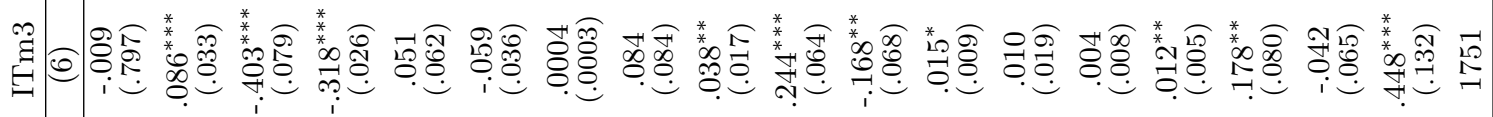

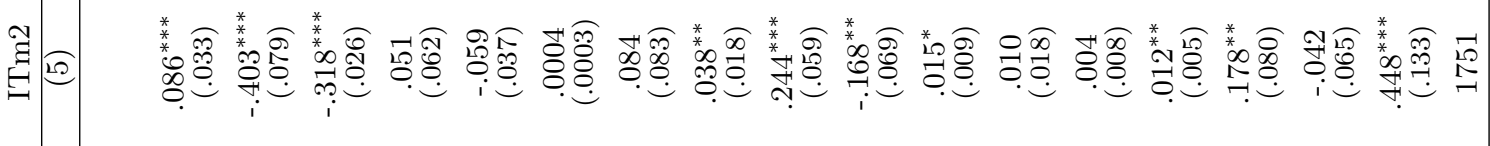

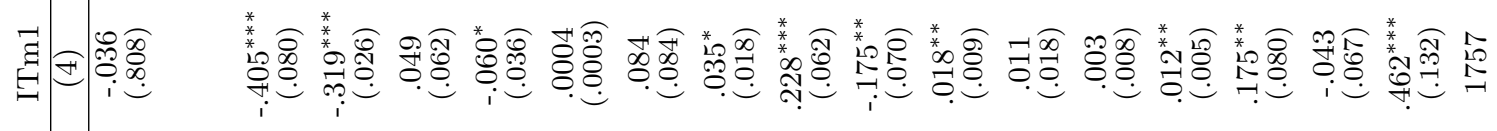

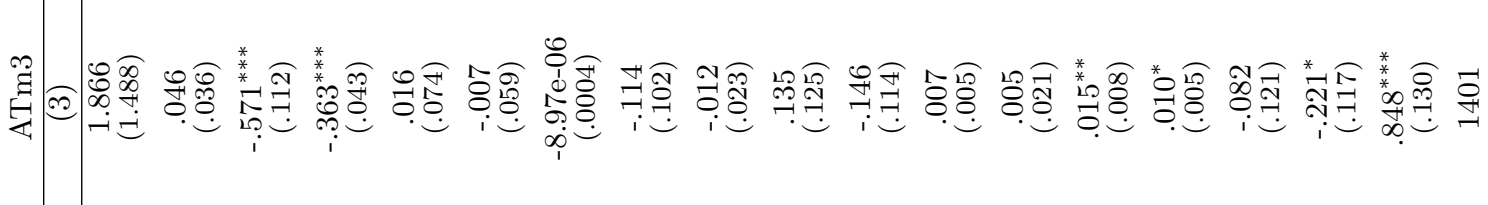

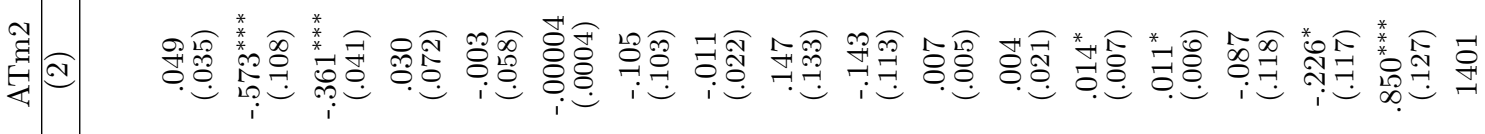

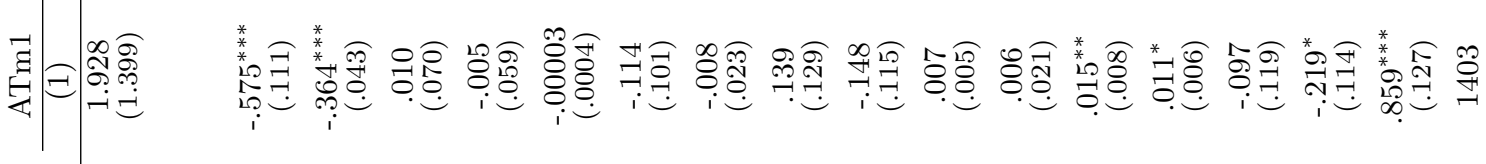

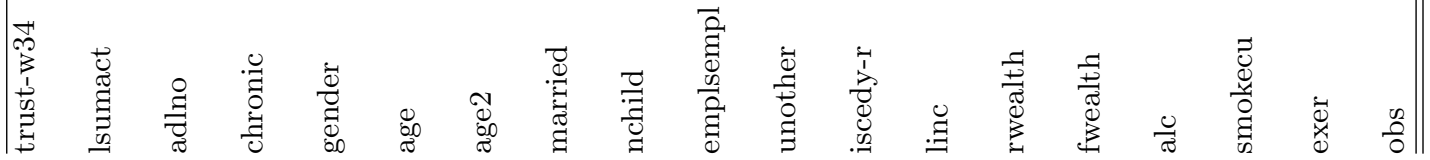

